\title{
Distinction without difference? Some considerations for 'race' in health genomics
}

\section{Bianca Dreyer ${ }^{1} \&$ Eric Oosenbrug ${ }^{2}$}

\section{Wilfrid Laurier University; 2. York University}

On September 20th 2008, Brian Sinclair, a 45-year-old double-amputee, died of a treatable bladder infection while waiting for care in the Emergency Room at Winnipeg's Health Sciences Centre. In their testimony, staff revealed that many had assumed the aboriginal man was drunk, homeless, or simply waiting for a ride - not someone in need of immediate medical attention ${ }^{1}$. The racial stereotype of the "drunken Aboriginal" was apparent in the staff's testimony. This case and many others demonstrate that race and racism are important determinants of health and health disparities within Canadian society ${ }^{1-3}$.

As medicine advances, new technologies offer opportunities to study health disparities between populations. To understand these populations, appropriate descriptors are necessary. The concept of race is one such readily available descriptor. While the study of genetic differences in health disparity across populations might provide important insight into disease prevention for minority populations, it also poses a number of challenges. Questions such as how to label the populations being studied - and how to make meaningful comparisons without propagating differences that could lead to further discrimination - are among the most difficult to answer. The emerging opportunities for health genomics, we argue, must be accompanied by efforts to critically examine how these developments and their use of race might inadvertently perpetuate or contribute to scientific racism. We will conclude with three recommendations for best practices.

Health genomics focuses on uncovering genetic differences in the incidence and prevalence of health conditions that exist among populations. It thereby provides new opportunities for understanding the interactions between individuals and environments ${ }^{4}$. With increasing ease of access to genetic information it is only a matter of time before this data will be used to directly inform clinical decision-making ${ }^{5}$. In 2005, BiDil became the first race- specific drug approved by the FDA, laying the groundwork for more targeted medicines to come ${ }^{6}$.

However, a topic rarely acknowledged or discussed among health genomics researchers are considerations of the merit and ethical consequence of the use of racial categories and conceptions of racial difference. Scientists have long affirmed the concept of race as being biologically meaningless ${ }^{7}$, yet improper and/or imprecise terminology remains a potent source for racial prejudice. Labels such as 'European,' 'African' or 'Asian' derived from necessarily limited samples, disregard significant diversity within continental regions and are therefore unlikely to have useful scientific meaning - particularly from the perspective of genetics at the global level ${ }^{8}$. Ironically, by constructing race as a meaningful variable in genetics research, scientists interested in addressing health disparities might inadvertently contribute to the patterns of injustice they seek to eliminate ${ }^{9}$.

It is not the association of groups to certain genetically linked diseases that is problematic, but the legitimization of clear, self-evident, natural (or genetic) boundaries between these groups ${ }^{9}$. Ascribing genetic susceptibility or predispositions to broad racial categories or continental groups can easily be misinterpreted as inherent (genetic) inferiority of one race compared to another. Thus, genetic findings may lead to the discrimination against constructed categories of people, while failing to acknowledge the variability within these group ${ }^{8}$. Given that findings from genomic research often support rather than contradict widely held assumptions about race, these findings not only spread rapidly in the general public, but they also tend to do so without notice ${ }^{9}$.

To help prevent the perpetuation of racial difference reified by genomics we propose the following three recommendations for scientists working in public health 
genomics:

1.) Avoid generalizations: Researchers need to clearly define their sample populations. Group differences should not be interpreted as legitimating clear and self-evident divisions between groups of people. Discussions of appropriate generalizability of results should also be considered.

2.) Avoid simplifications: Researchers need to anticipate how their research will be used by health care professionals and the media, and advocate for a correct translation of their findings.

3.) Avoid problematization: Researchers need to practice caution when ascribing value to group differences to avoid forming a discourse of inferiority and superiority between groups.

Central to our recommendations is a commitment to scientific accuracy and an acknowledgement that racial labels have consequences for which we, as researchers and producers of knowledge, are responsible. Further, it should be a primary concern to consider how the public may perceive and respond to the descriptors that appear in research papers and media articles ${ }^{8}$.

Although we cannot predict if and how health genomics will contribute to scientific racism, there is a need to anticipate the various potential social and ethical problems that arise from population descriptors. As we learned from the case of Mr. Sinclair, racial stereotypes can have disastrous consequences. While examining health disparities between populations is an important endeavour for genomics, the distinction of populations based on race might perpetuate rather than mitigate poor health - legitimizing distinction with questionable differences.

\section{References}

1. Brian Sinclair inquest: aboriginals face racism in ERs, expert says. Global News [Internet]. 2014 June 10 [cited 2015 Mar 22]. Available from: http:// globalnews.ca/news/1385222/bring-sinclair-inquest-aboriginals-faceracism-in-ers-expert-says/

2. Racism against aboriginal people in health-care system 'pervasive': study. CBC News [Internet]. 2015 February 3 [cited 2015 Mar 22] Available from: http://www.cbc.ca/news/aboriginal/racism-against-aboriginal-people-inhealth-care-system-pervasive-study-1.2942644.

3. Krieger N. Stormy weather: race, gene expression, and the science of health disparities, Am J Public Health. 2005;95(12):2155-60.

4. Zusevics, KL. Public health genomics: a new space for a dialogue on racism through Community Based Participatory Research. Public Health. 2013;127:981-983.

5. Hamburg MA and Collins FS. The Path to Personalized Medicine. N Engl J Med 2010; 363:301-304

6. Kahn J. Misreading race and genomics after BiDil, Correspondence. Nature Genetics. 2005;37:655-656.

7. Morning A. The Nature of Race: How Scientists Think and Teach About Human Difference. Berkeley and Los Angeles: University of California Press; 2011.

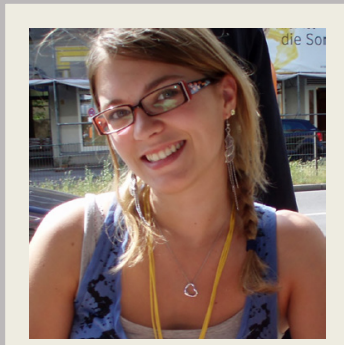

\section{Bianca Dreyer}

Bianca is a first year Master's student in Social Psychology at Wilfrid Laurier University. Her current research focuses on how genetic information shapes people's beliefs and attitudes in regards to important social issues. Bianca is a passionate advocate of social justice research and plans to integrate her interdisciplinary interests in biology and sociology with social psychological research.

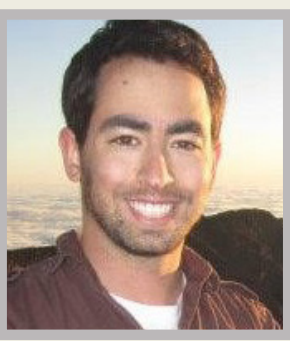

\section{Eric Oosenbrug}

Eric is a PhD student in York University's History \& Theory of Psychology program. His work focuses on recent neuro-history in which he engages contemporary pain research, critical health psychology, anthropology of the body and the nascent field of insect studies. More information can be found on his personal website: http://ericoosenbrug.com 